\title{
Seminar Publikasi Karya Ilmiah: Strategi Publikasi Artikel dan Kiat-Kiat Lolos Publikasi dalam Jurnal
}

\author{
Susdarwati, Arifian Dimas \\ STKIP Modern Ngawi \\ (susdarwati88sains@gmail.com, 082332728881)
}

\begin{abstract}
ABSTRAK
Dirjen Dikti Kemdikbud mewajibkan seluruh mahasiswa membuat dan mempublikasikan tulisan karya ilmiahnya sebagai salah satu penentu kelulusan, baik dalam jurnal online maupun jurnal cetak. Publikasi karya ilmiah menjadi agenda penting untuk STKIP PGRI Nganjuk. Tujuan kegiatan pengabdian ini adalah untuk meningkatkan wawasan dan pengetahuan pada mahasiswa STKIP PGRI Nganjuk tentang strategi publikasi artikel dan kiat-kiat lolos publikasi dalam jurnal. Metode kegiatan yaitu realisasi MoU dengan STKIP PGRI Nganjuk, menetapkan jadwal dan materi, dan menyampaikam materi dalam bentuk seminar melalui metode ceramah bervariasi dan tanya jawab. Hasil pengabdian kepada masyarakat adalah: 1) keberhasilan target jumlah peserta seminar mencapai $90 \%$ yaitu 220 mahasiwa, 2) ketercapaian tujuan kegiatan secara umum telah tercapai yaitu wawasan dan pengetahuan mahasiswa STKIP PGRI Nganjuk tentang strategi publikasi artikel dan kiat-kiat lolos publikasi dalam jurnal mengalami peningkatan, dan 3) ketercapaian target materi pada kegiatan pengabdian masyarakat ini cukup baik terbukti materi telah disampaikan secara keseluruhan dan adanya kesesuaian materi dengan kebutuhan mahasiswa.
\end{abstract}

Kata kunci : Strategi publikasi artikel, jurnal

\begin{abstract}
The Directorate General of Higher Education, Kemdikbud requires all students to write and publish scientific papers as one of the determinants of graduation, both in online journals and in print journals. Publication of scientific papers is an important agenda for STKIP PGRI Nganjuk. The purpose of this service activity is to increase insight and knowledge of STKIP PGRI Nganjuk students about article publication strategies and tips for passing publication in journals. The method of activity is the realization of the MoU with STKIP PGRI Nganjuk, setting schedules and materials, and delivering the material in the form of seminars through various lecture methods and question and answer. The results of community service are: 1) the success of the target number of seminar participants reached 90\%, namely 220 students, 2) the achievement of the activity objectives in general has been achieved, namely the insights and knowledge of STKIP PGRI Nganjuk students about article publication strategies and tips for passing publication in experienced journals increase, and 3) the achievement of the material targets in this community service activity is quite good, it is proven that the material has been delivered as a whole and that the material conforms to the needs of students.
\end{abstract}

Keywords : Article publication strategies, journals 


\section{PENDAHULUAN}

Publikasi karya ilmiah menjadi agenda penting bagi para akademisi, bukan hanya sebagai prasyarat semata tetapi hal tersebut juga dilakukan untuk masa depan bangsa Indonesia. Per 27 Januari 2012 Direktur Jenderal Pendidikan Tinggi Kementerian Pendidikan dan Kebudayaan mengeluarkan surat edaran bahwa seluruh mahasiswa (S-1, S-2, dan S-3) wajib membuat dan mempublikasikan tulisan karya ilmiahnya sebagai salah satu penentu kelulusan, baik dalam jurnal online maupun jurnal cetak. Secara sentral kebijakan penelitian di Indonesia mengarahkan segenap institusi perguruan tinggi untuk meningkatkan mutu dan kualitas penelitian, baik substansi maupun administrasi (Darmalaksana, 2017).

Publikasi ilmiah menjadi syarat wajib bagi mahasiswa program Sarjana untuk memperoleh kelulusan (Yosua P.W Simaremare, 2013). Sebagai ahli, seorang sarjana harus memiliki kemampuan menulis secara ilmiah. Termasuk menguasai tata cara penulisan ilmiah yang baik, menulis karya ilmiah baik dari rangkuman tugas, penelitian kecil, mapun ringkasan dari skripsi yang dibuatnya. Ketika seorang sarjana telah mahir menulis ilmiah, ke depannya diharapkan tidak akan kesulitan ketika membuat karya ilmiah di jenjang selanjutnya. Aturan ini dapat menciptakan kuantitas dan kualitas karya ilmiah yang dihasilkan oleh Indonesia.

Ketika lanjut ke Magister atau Doktor, kualitas tulisan ilmiahnya bisa meningkat, berwawasan global, dan bisa terbit di jurnal- jurnal yang bereputasi. Aturan ini sengaja dibuat untuk mengejar ketertinggalan Indonesia dalam hal membuat karya ilmiah. Berdasarkan data Kemdikbud, jumlah karya ilmiah yang dihasilkan perguruan tinggi Indonesia saat ini masih rendah, hanya sepertujuh jika dibandingkan dengan negara tetangga, Malaysia. Bagi mahasiswa S-1, untuk lulus program Sarjana harus menghasilkan makalah yang terbit pada jurnal ilmiah. Sementara, mahasiswa S-2 diharuskan menghasilkan makalah yang terbit pada jurnal ilmiah nasional, diutamakan yang terakreditasi Dikti. Adapun mahasiswa program Doktor harus telah menghasilkan makalah yang diterima untuk terbit pada jurnal internasional.

Publikasi ilmiah menjadi syarat wajib bagi mahasiswa program Sarjana STKIP PGRI Nganjuk untuk memperoleh kelulusan. Karya ilmiah yang dipublikasikan merupakan kontribusi pemikiran untuk menjawab berbagai permasalahan yang terjadi pada kehidupan manusia (Rohmah, et al., 2016). Publikasi ilmiah yang baik dimulai dari memilih jurnal berkualitas, jurnal berkualitas dapat dicirikan dengan adanya terindeks-nya jurnal tersebut seperti google scholar, DOAJ, Scopus, Thomson and Reuters, jurnal terakreditasi nasional atau internasional sesuai yang dipersyaratkan serta menghindari jurnal predator (Suryana, 2018).

Mempublikasikan hasil penelitian merupakan tanggungjawab sosial-ilmiah dari seorang peneliti (I Made Supartha Utama, 
2017). Tanpa publikasi maka hasil penelitian menjadi tidak bermakna dan bermanfaat.

Publikasi hasil penelitian di jurnal (terbitan berkala) ilmiah adalah salah satu segi penting dari kegiatan ilmiah. Jurnal adalah bentuk terbitan yang berfungsi meregistrasi kegiatan kecendekiaan, mensertifikasi hasil kegiatan yang memenuhi persyaratan ilmiah minimum, mendiseminasikannya secara meluas kepada khalayak ramai, dan mengarsipkan semua temuan hasil kegiatan kecendekiaan ilmuwan dan pandit yang dimuatnya (Lukman, 2016).

Menurut I Made Supartha Utama (2017) bahwa pemilihan jurnal untuk publikasi adalah penting terutama untuk mengetahui seberapa cepat proses publikasi yang harus dilalui (rapid review), apakah jurnal yang dijadikan tempat publikasi adalah terakreditasi atau bermutu (prestige), apakah banyak orang di bidang anda membaca jurnal tersebut (circulation), dan apakah peneliti lainnya akan mensitasi hasil karya anda (citation).

Tujuan kegiatan pengabdian ini adalah untuk meningkatkan wawasan dan pengetahuan pada mahasiswa STKIP PGRI Nganjuk tentang strategi publikasi artikel dan kiat-kiat lolos publikasi dalam jurnal.

\section{BAHAN DAN METODE}

Sasaran kegiatan pengabdian masyarakat ini adalah mahasiswa STKIP PGRI Nganjuk. Kegiatan ini dilaksanakan di Jalan A.R. Saleh nomor 21 Kauman Kecamatan Nganjuk dengan jumlah khalayak sasaran yaitu 220 orang. Adapun yang menjadi narasumber dalam kegiatan ini adalah Susdarwati, M.Pd. yang merupakan dosen Program Studi Pendidikan IPA STKIP Modern Ngawi dan Dr. Mumun Nurmilawati, M.Pd. yang merupakan dosen Program Studi Pendidikan Biologi UNP Kediri.

Langkah-langkah kegiatan pengabdian ini antara lain: 1) realisasi MoU dengan STKIP PGRI Nganjuk di bidang Pengabdian kepada Masyarakat, 2) menetapkan jadwal seminar publikasi ilmiah, 3) menetapkan materi yang akan diberikan dalam kegiatan tersebut, dan 4) menyampaikan materi dalam bentuk seminar.

Metode yang digunakan dalam pelaksanaan seminar yaitu ceramah bervariasi dan Tanya jawab. Ceramah bervariasi yaitu pemateri menyampaikan konsep-konsep yang penting untuk dimengerti dan dikuasai oleh Audinece. Penggunaan metode ini dengan pertimbangan bahwa metode ceramah yang dikombinasikan dengan demonstrasi dapat memberikan materi yang relatif banyak secara padat, cepat, dan mudah. Tanya jawab yaitu metode ini dipilih untuk mengetahui sejauh mana masyarakat dapat menerima dan memahami apa yang telah diberikan. Penggunaan metode ini dengan pertimbangan bahwa metode tanya jawab dapat lebih menghidupkan forum serta narasumber dapat langsung mengetahui apakah yang disampaikan dapat dipahami oleh audience.

Langkah-langkah kegiatan yang dilakukan adalah seminar dengan tahapan sebagai berikut: 1) pembukaan, 
menyanyikan lagu kebangsaan Indonesia Raya, 3) sambutan oleh Ketua Yayasan STKIP PGRI Nganjuk dan ketua panitia, 4) moderator meyampaikan Curiculum Vitae narasumber, 5) narasumber memberikan materi pada peserta tentang strategi publikasi artikel dan kiat-kiat lolos publikasi dalam jurnal, 6) memberikan kesempatan tanya jawab pada peserta terkait hal-hal yang masih belum dipahami, 7) memberikan Merchandise kepada peserta yang sudah bertanya serta pemberian sertifikat dan souvenir untuk narasumber, dan 8) penutup.

\section{HASIL}

Kegiatan pengabdian masyarakat yang dilaksanakan dengan acara tatap muka dalam bentuk seminar ini berjalan dengan baik dan lancar. Kegiatan ini dilaksanakan dengan metode ceramah bervariasi dan tanya jawab. Kegiatan ini dilaksanakan dalam waktu satu kali pertemuan, yakni pada hari Jumat, 13 Desember 2019 dari pukul 13.00-16.30 WIB. Peserta kegiatan berjumlah 220 mahasiswa STKIP PGRI Nganjuk.

Pelaksanaan kegiatan pengabdian masyarakat ini terbagi menjadi beberapa materi, adapaun materinya adalah: 1) mengapa harus publikasi, 2) mengapa perlu menulis artikel yang bagus, 3) bagaimana manuskrip yang baik; 4) bagaimana menghadapi revisi dan respon kepada penelaah; 5) bagaimana isu-isu etik; dan 6) bagaimana bisa diterima untuk publikasi.

Kegiatan yang diawali dengan pembukaan oleh Pembawa Acara ini kemudian dilanjutkan dengan menyanyikan lagu kebangsaan Indonesia Raya. Ketua Panitia seminar memberikan sambutan dilanjutkan oleh sambutan Bapak. Ketua Yayasan STKIP PGRI Nganjuk sekaligus membuka acara. Moderator memandu acara inti. Moderator meyampaikan Curiculum Vitae dilanjutkan narasumber menyampaikan materi. Narasumber memberikan materi pada peserta tentang strategi publikasi atikel dan kiat-kiat lolos publikasi dalam jurnal. Setelah itu, sesi tanya jawab memberikan kesempatan tanya jawab pada peserta terkait hal-hal yang masih belum dipahami. Kemudian pemberian Merchandise kepada peserta yang sudah bertanya serta pemberian sertifikat dan souvenir untuk narasumber. Setelah itu, acara seminar ditutup dengan doa kemudian dokumentasi.

Berbagai pertanyaan diajukan secara antusias oleh mahasiswa dalam sesi tanya jawab. Secara garis besar inti dari pertanyaan mahasiswa adalah bagaimana cara agar artikel langsung diterima tanpa revisi dan bagaimana cara mengetahui tempat penerbit jurnal yang sesuai dengan bidang ilmu. Narasumber menjelaskan agar artikel diterima yaitu menggunakan makna ACCEPTANCE. Kepanjangannya adalah 1) Attention to details, 2) Check and double check your work, 3) Consider the reviewers comments, 4) English mus be as good as possible, 5) Presentation is important, 6) Take your time with revision, 7) Acknowledge those who have helped you, 8) New, original and previously unpublished, 9) Critically evaluate your own 
manuscript, and 10) Ethical rules must be obeyed.

Program pengabdian berupa seminar ini diharapkan dapat menambah pengetahuan, wawasan, serta pemahaman mahasiswa dalam hal publikasi artikel dalam bentuk jurnal. Diharapkan mahasiswa dapat menyusun artikel sesuai kaidah penulisan dengan tepat.

\section{PEMBAHASAN}

Hasil pelaksanaan kegiatan pengabdian masyarakat ini secara garis besar mencakup beberapa komponen, yaitu:

1. Keberhasilan target jumlah peserta seminar Target peserta seminar seperti yang direncanakan sebelumnya adalah 250 mahasiswa STKIP PGRI Nganjuk. Dalam pelaksanaannya, kegiatan ini dihadiri oleh 220 orang. Dengan demikian dapat dikatakan bahwa jumlah peserta mencapai $90 \%$. Angka tersebut menunjukkan bahwa kegiatan pengabdian masyarakat ini apabila dilihat dari jumlah peserta yang mengikuti dapat dikatakan berhasil.

\section{Ketercapaian tujuan kegiatan}

Ketercapaian tujuan kegiatan secara umum telah tercapai. Wawasan serta pengetahuan mahasiswa STKIP PGRI Nganjuk tentang strategi publikasi artikel dan kiat-kiat lolos publikasi dalam jurnal mengalami peningkatan. Antusias mahasiswa untuk bertanya baik sekali. Terdapat 5 mahasiswa yang bertanya dan yang bertanya diberi merchandise.

3. Ketercapaian target materi yang telah direncanakan.
Ketercapaian target materi pada kegiatan pengabdian masyarakat ini cukup baik. Hal ini dikarenakan adanya kesesuaian materi dengan kebutuhan mahasiswa serta materi telah disampaikan secara keseluruhan.

Jadi secara keseluruhan kegiatan pengabdian masyarakat ini dapat dikatakan berhasil. Keberhasilan ini selain diukur dari tiga komponen di atas, juga dapat dilihat dari kepuasan peserta setelah mengikuti kegiatan. Manfaat yang diperoleh mahasiswa adalah dapat menambah semangat dan motivasi untuk publikasi artikel dan bisa lolos di jurnal yang sesuai dengan harapan.

\section{KESIMPULAN DAN SARAN}

Kesimpulan kegiatan pengabdian dalam bentuk seminar ini adalah wawasan dan pengetahuan mahasiswa STKIP PGRI Nganjuk tentang strategi publikasi artikel dan kiat-kiat lolos publikasi dalam jurnal mengalami peningkatan. Adanya respon yang positif dari peserta karena kegiatan ini merupakan kebutuhan mahasiswa dalam rangka peningkatan kemampuan ilmiahnya.

Berdasarkan evaluasi yang telah dilakukan, saran kegiatan ini adalah ada tindak lanjut berupa pelatihan untuk membuat artikel yang sesuai sesuai denag bidang masing-masing yang siap dipublikasikan.

\section{UCAPAN TERIMA KASIH}

Pelaksanaan kegiatan pengabdian masyarakat dalam bentuk Seminar Publikasi Karya Ilmiah ini dapat diselenggarakan dengan baik dan berjalan lancar karena 
mendapat dukungan dari beberapa pihak yaitu

STKIP PGRI Nganjuk dan STKIP Modern Ngawi.

\section{DAFTAR PUSTAKA}

Darmalaksana, W., 2017. Riset Berbasis Outcome. Jurnal Riset dan Inovasi, p. 3

I Made Supartha Utama. 2017. Bagaimana Menulis dan Mempublikasikan Artikel Ilmiah. Bali: Fakultas Teknologi Pertanian Universitas Udayana.
Lukman. 2016. Strategi Peningkatan Publikasi Ilmiah Bereputasi. Surabaya: PDII LIPI.

Rohmah, N., Huda, M. \& Kusmintardjo, A. Y. 2016. Strategi Peningkatan Kemampuan Dosen dalam Penulisan Karya Ilmiah (Studi Multi Kasus pada UNISDA dan STAIDRA di Kabupaten Lamongan). Jurnal Pendidikan, 1(7), pp. 1312-1322.

Suryana, 2018. Korespondensi dalam Publikasi Ilmiah. Jurnal Perspektif, 2(1), pp. 1-8.

Yosua P.W Simaremare. 2013. Perancangan dan Pembuatan Aplikasi Manajemen Publikasi Ilmiah Berbasis Online pada Jurnal SISFO. Jurnal Teknik POMITS, 2(3).

\section{LAMPIRAN}

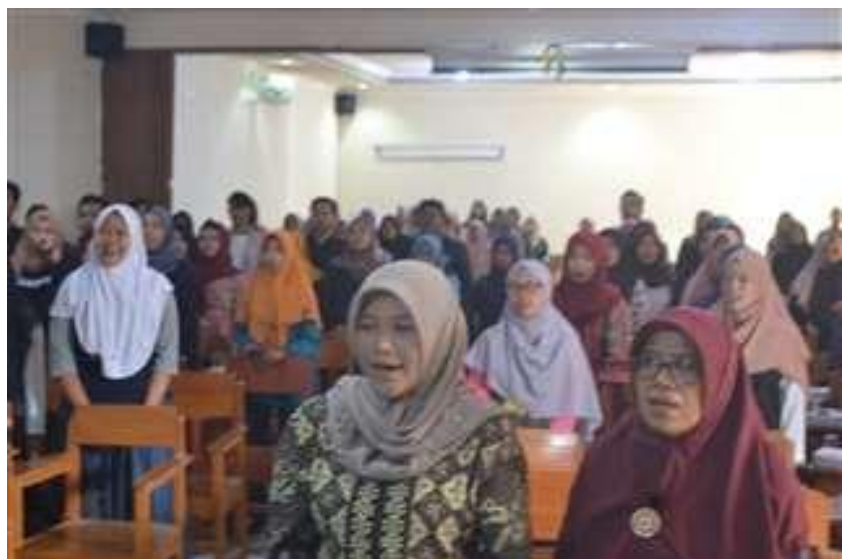

Gambar 1. Pembukaan menyanyikan Lagu Indonesia Raya

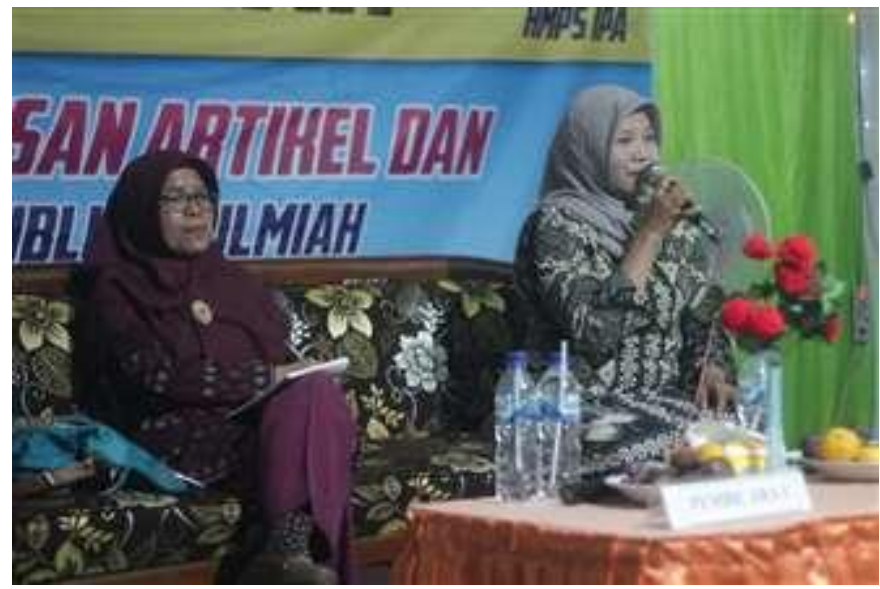

Gambar 2. Penyampaian Materi 


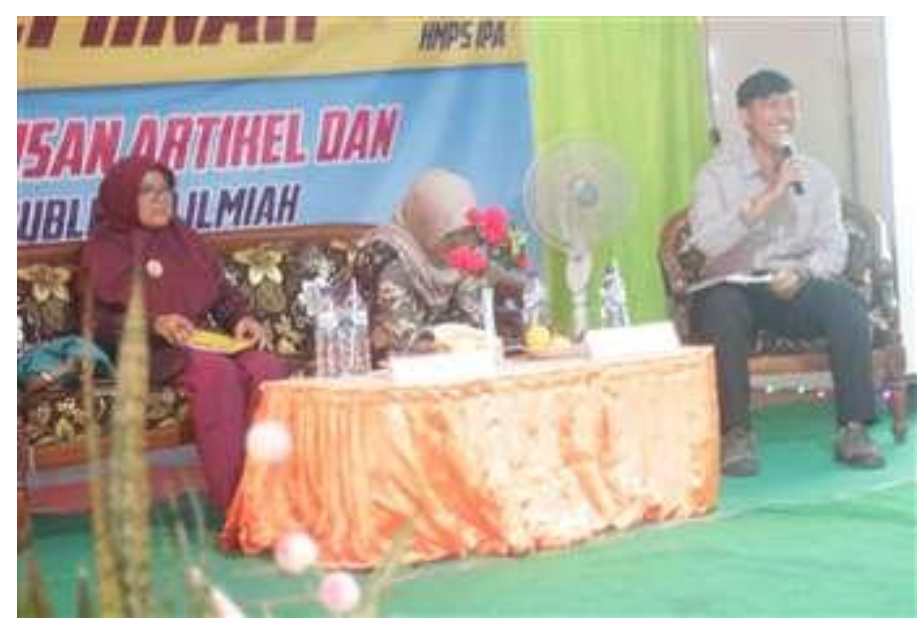

Gambar 3. Sesi Tanya Jawab

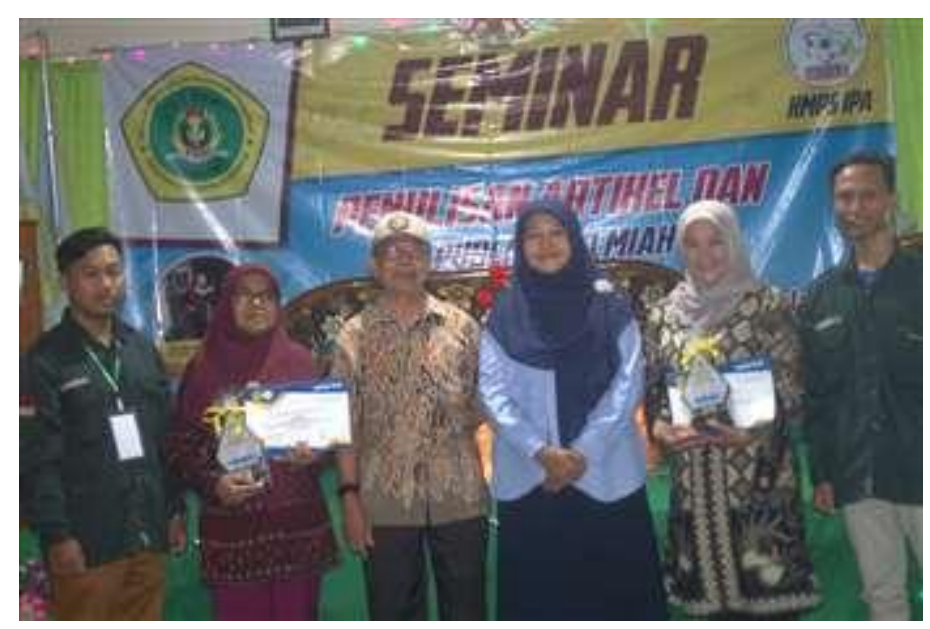

Gambar 4. Penyerahan Sertifikat dan Vandel sebagai Pemateri

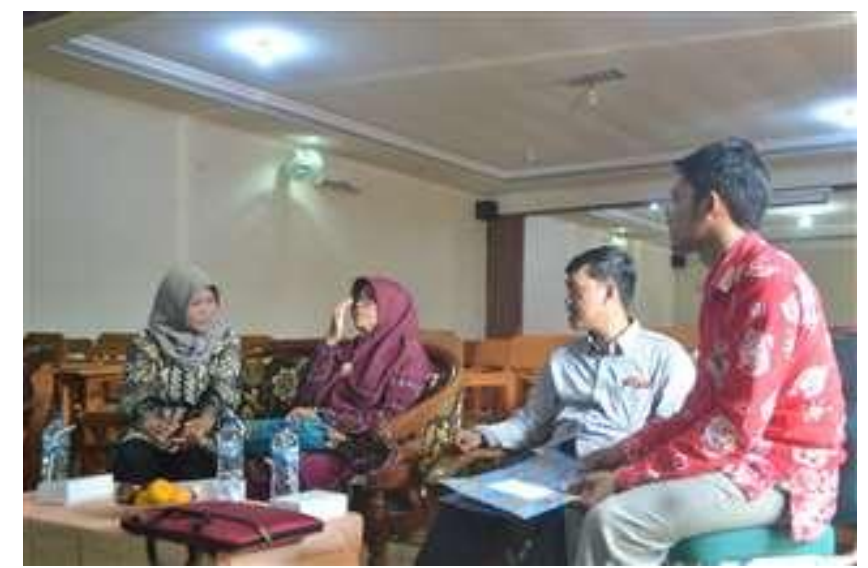

Gambar 5. Pengisian Angket Realisasi MoU STKIP PGRI Nganjuk 